\title{
Immuno-PET of Murine T Cell Reconstitution Postadoptive Stem Cell Transplantation Using Anti-CD4 and Anti-CD8 Cys-Diabodies
}

\author{
Richard Tavaré $^{1}$, Melissa N. McCracken², Kirstin A. Zettlitz ${ }^{1}$, Felix B. Salazar ${ }^{1}$, Tove Olafsen ${ }^{1}$, Owen N. Witte ${ }^{2-5}$, \\ and Anna M. $\mathrm{Wu}^{1}$ \\ ${ }^{I}$ Crump Institute for Molecular Imaging, Department of Molecular and Medical Pharmacology, David Geffen School of Medicine at \\ UCLA, Los Angeles, California; ${ }^{2}$ Department of Molecular and Medical Pharmacology, David Geffen School of Medicine at UCLA, \\ Los Angeles, California; ${ }^{3}$ Howard Hughes Medical Institute at UCLA, Los Angeles, California; ${ }^{4}$ Department of Microbiology, \\ Immunology and Molecular Genetics at UCLA, Los Angeles, California; and ${ }^{5}$ Eli and Edythe Broad Center of Regenerative Medicine \\ and Stem Cell Research at UCLA, Los Angeles, California
}

The proliferation and trafficking of $\mathrm{T}$ lymphocytes in immune responses are crucial events in determining inflammatory responses. To study whole-body T lymphocyte dynamics noninvasively in vivo, we generated anti-CD4 and -CD8 cys-diabodies (cDbs) derived from the parental antibody hybridomas GK1.5 and 2.43, respectively, for ${ }^{89} \mathrm{Zr}$-immunoPET detection of helper and cytotoxic $T$ cell populations. Methods: Anti-CD4 and -CD8 cDbs were engineered, produced via mammalian expression, purified using immobilized metal affinity chromatography, and characterized for $\mathrm{T}$ cell binding. The cDbs were site-specifically conjugated to maleimide-desferrioxamine for ${ }^{89} \mathrm{Zr}$ radiolabeling and subsequent small-animal PET/CT acquisition and ex vivo biodistribution in both wild-type mice and a model of hematopoietic stem cell (HSC) transplantation. Results: Immuno-PET and biodistribution studies demonstrate targeting and visualization of CD4 and CD8 T cell populations in vivo in the spleen and lymph nodes of wild-type mice, with specificity confirmed through in vivo blocking and depletion studies. Subsequently, a murine model of HSC transplantation demonstrated successful in vivo detection of T cell repopulation at 2, 4, and 8 wk after HSC transplantation using the ${ }^{89} \mathrm{Zr}$-radiolabeled anti-CD4 and -CD8 cDbs. Conclusion: These newly developed anti-CD4 and -CD8 immuno-PET reagents represent a powerful resource to monitor $T$ cell expansion, localization, and novel engraftment protocols. Future potential applications of $\mathrm{T}$ cell-targeted immuno-PET include monitoring immune cell subsets in response to immunotherapy, autoimmunity, and lymphoproliferative disorders, contributing overall to preclinical immune cell monitoring.

Key Words: immuno-PET; $\mathrm{CD}^{+}$and $\mathrm{CD}^{+} \mathrm{T}$ cells; antibody fragments; hematopoietic stem cell transplantation; ${ }^{89} \mathrm{Zr}$

J Nucl Med 2015; 56:1258-1264

DOI: 10.2967/jnumed.114.153338

Received Jan. 6, 2015; revision accepted Apr. 9, 2015.

For correspondence or reprints contact either of the following:

Richard Tavaré, California NanoSystems Institute 4350B, University of

California Los Angeles, 570 Westwood Plaza, Los Angeles, CA 90095-1770. E-mail: rtavare@mednet.ucla.edu

Anna M. Wu, California NanoSystems Institute 4335, University of

California Los Angeles, 570 Westwood Plaza, Los Angeles, CA 90095-1770.

E-mail: awu@mednet.ucla.edu

Published online May 7, 2015

COPYRIGHT (c) 2015 by the Society of Nuclear Medicine and Molecular Imaging, Inc.
$\mathbf{T}$

he ability to noninvasively monitor immune cells, specifically $\mathrm{T}$ cells, in the fields of oncology, immunotherapy, autoimmunity, and infection is difficult because of the complex nature of heterogeneous lymphocyte localization, proliferation, and migration. Lymphocyte monitoring during immunotherapy protocols, such as detection of circulating lymphocytes from whole blood or tumorinfiltrating lymphocytes from tissue biopsy, does not provide the full range of dynamic and spatial information needed. With the expanding implementation of immunotherapies, such as adoptive $\mathrm{T}$ cell transfer, hematopoietic stem cell (HSC) or progenitor cell transfer, small-molecule and antibody-based immunotherapies, and combinations thereof, whole-body immuno-PET targeting of immune cell subtypes can potentially provide spatial and temporal information that is impossible using current methods.

Immuno-PET takes advantage of the exquisite specificity and affinity of antibodies or antibody fragments and the sensitivity of PET (1-3). Intact antibodies have been engineered into bivalent antibody fragments such as the cys-diabody $(\mathrm{cDb}$; dimer of $\mathrm{scFv}$; Fig. 1A) or minibody $\left(\mathrm{Mb}\right.$; dimer of $\left.\mathrm{scFv}_{-} \mathrm{C}_{\mathrm{H}} 3\right)$ to enhance immuno-PET imaging characteristics, including rapid clearance for high target-to-background images at short times after injection, avidity, engineered sites for site-specific conjugation, and lack of Fc effector functions, among others (4).

Non-antibody-based methods to detect lymphocytes using PET include direct cell labeling of cells ex vivo (5-7), reporter gene imaging of ex vivo genetically modified $\mathrm{T}$ cells $(8)$, or the use of metabolic probes such as ${ }^{18} \mathrm{~F}$-FDG, $33^{\prime}$-deoxy- $3^{\prime}-{ }^{18} \mathrm{~F}$-fluorothymidine, 1-(2'-deoxy-2' ${ }^{18}$ F-fluoroarabinofuranosyl) cytosine, and $2^{\prime}$-deoxy$2^{\prime}{ }^{18}$ F-fluoro-9- $\beta$-arabinofuranosylguanine (9-13). Direct cell labeling suffers from limitations of radionuclide half-life, probe dilution due to cell division, and potential toxic effects due to the radiosensitivity of lymphocytes. Reporter gene tracking of $\mathrm{T}$ cells allows for longitudinal tracking, repeated monitoring, and signal amplification due to cell division, but it requires the transfection of cells with exogenous DNA and the development of nonimmunogenic reporters for translation $(14,15)$. The use of radiolabeled metabolic probes does not require ex vivo manipulation of cells, but these probes are either not specific for $\mathrm{T}$ cells (e.g., ${ }^{18} \mathrm{~F}-\mathrm{FDG}$ and ${ }^{18} \mathrm{~F}-\mathrm{FLT}$ ) or they target proliferating $\mathrm{T}$ cells in secondary lymphoid organs and fail to detect 


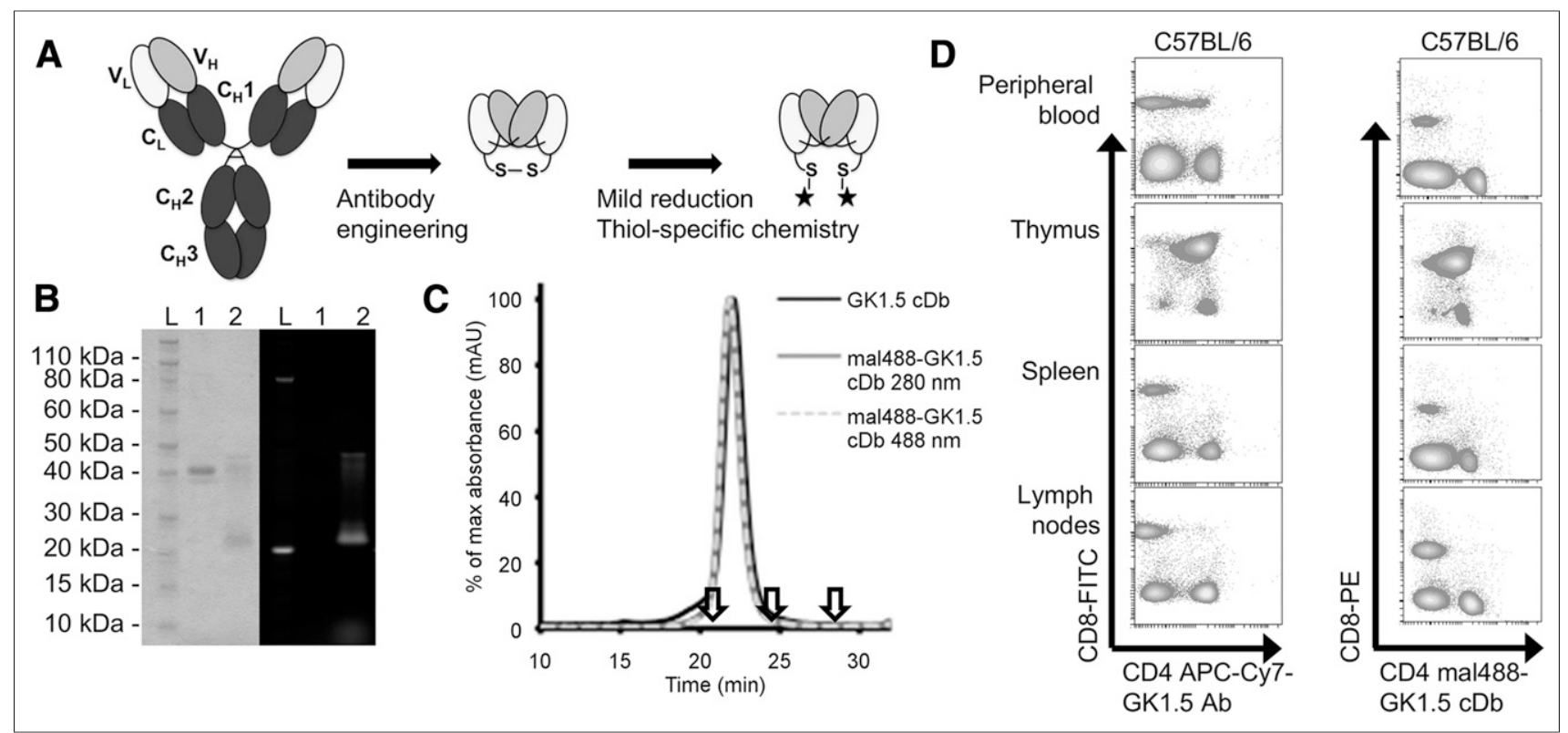

FIGURE 1. Anti-CD4 GK1.5 cDb characterization. (A) Schematic of intact antibody and engineered cDbs for site-specific conjugation of fluorescent or metal chelator moieties via thiol-specific chemistry. (B) SDS-PAGE gel (left) of purified GK1.5 cDb (Lane 1) and mal488-GK1.5 cDb (Lane 2) for fluorescent flow cytometry binding assays $(\mathrm{L}=$ molecular weight ladder). The ultraviolet image (right) of same gel shows mal488 conjugated to GK1.5 $\mathrm{cDb}$. (C) SEC demonstrates that conjugation to mal488 did not disrupt diabody conformation. Reference arrows indicate albumin (66 kDa) at $20.8 \mathrm{~min}$, carbonic anhydrase $(29 \mathrm{kDa})$ at $24.7 \mathrm{~min}$, and cytochrome $\mathrm{C}(12.4 \mathrm{kDa})$ at $27.4 \mathrm{~min}$. (D) Flow cytometry of single-cell suspensions from blood, thymus, spleen, and LNs of C57BL/6 mice compares binding of commercial anti-CD4-APC-Cy7 clone GK1.5 (left) and mal488-GK1.5 cDb (right). $\mathrm{Ab}=$ antibody; FITC = fluorescein isothiocyanate; $\mathrm{PE}=$ phycoerythrin.

tumor-infiltrating lymphocytes (e.g., 1-(2'-deoxy-2'-18 F)fluoroarabinofuranosyl) cytosine).

HSC therapy has become an attractive approach for the treatment of multiple malignancies (16). Currently, many stem or progenitor cell therapies involving $\mathrm{T}$ cell receptor- or chimeric antigen receptortargeting epitopes expressed on malignant cells are under development for clinical translation (17-20). Previous work using PET to detect HSC transfer and immune cell engraftment uses reporter genes to image total cell engraftment as opposed to lineage-specific repopulation $(14,21)$. Here we report the development of anti-CD4 and -CD8 cys-diabodies (cDbs) radiolabeled with ${ }^{89} \mathrm{Zr}$ for direct immuno-PET detection of $\mathrm{CD}^{+}{ }^{+}$and $\mathrm{CD} 8^{+} \mathrm{T}$ cells with the goal of detecting helper and cytotoxic lymphocyte repopulation after HSC therapy.

\section{MATERIALS AND METHODS}

C57BL/6, C57BL/6 SJL, and AKR mice were obtained from the Jackson Laboratories and housed and maintained by the Department of Laboratory Animal Medicine at the University of California, Los Angeles (UCLA). The UCLA Chancellor's Animal Research Committee approved protocols for all animal studies.

Detailed information regarding construction of anti-CD4 and -CD8 diabodies, protein expression and purification, flow cytometry, immunoPET, biodistribution, and data analysis can be found in the supplemental materials (available at http://jnm.snmjournals.org).

\section{$N-(3,11,14,22,25,33-H e x a o x o-4,10,15,21,26$,} 32-Hexaaaza-10,21,32-Trihydroxytetratriacontane) Maleimide (malDFO) Conjugation

The cDbs at $1-2.2 \mathrm{mg} / \mathrm{mL}$ were then reduced with 20 -fold molar excess of tris(2-carboxyethyl)phosphine (Pierce) for $30 \mathrm{~min}$ at room temperature. A 20-fold molar excess of malDFO (Macrocyclics) was then added and allowed to react for $2 \mathrm{~h}$ at room temperature. Excess malDFO was removed using PD-10 desalting columns (GE Healthcare) that were preequilibrated with phosphate-buffered saline. Eluted protein was concentrated with Amicon Ultra centrifugal filters $(0.5 \mathrm{~mL}$ and $10 \mathrm{kDa}$ MWCO; Milipore). Conjugation efficiency was measured qualitatively by size-exclusion chromatography (SEC) using a Superdex 75 column (GE Healthcare) on an AKTA purifier and sodium dodecyl sulphate-polyacrylamide gel electrophoresis (SDS-PAGE)-Coomassie stain analysis.

\section{Zr Radiolabeling}

${ }^{89} \mathrm{Zr}$-oxalate was obtained from Washington University School of Medicine, Division of Radiologic Sciences, or from 3D Imaging LLC. On arrival, ${ }^{89} \mathrm{Zr}$-oxalate was diluted with $40 \%$ (v/v) $2 \mathrm{M} \mathrm{Na}_{2} \mathrm{CO}_{3}$ and allowed to incubate for $3 \mathrm{~min}$. The activity was then diluted with a 2.5× volume of $1 \mathrm{M} \mathrm{N}$-(2-hydroxyethyl)piperazine- $N$-(2-ethanesulfonic acid) (pH 7.0). Final $\mathrm{pH}$ was checked with pHydrion plastic indicator strips (Micro Essential Laboratory) to confirm a $\mathrm{pH}$ of 7. MalDFOconjugated protein was incubated for $1 \mathrm{~h}$ at room temperature at about $148-185 \mathrm{kBq} / \mu \mathrm{g}(4-5 \mu \mathrm{Ci} / \mu \mathrm{g})$. Radiolabeling efficiency was measured by instant thin-layer chromatography (ITLC) (Biodex Medical Systems) using $20 \mathrm{mM}$ citrate buffer, $\mathrm{pH}$ 5.6, as the mobile phase with a Wizard 3" 1480 Automatic Gamma Counter (Perkin-Elmer). Protein was purified using either Bio-Spin 6 columns (Bio-Rad) or PD-10 columns equilibrated with phosphate-buffered saline. Radiochemical purity was assessed by ITLC as above.

\section{HSC Transplantation}

5-fluorouracil (150 mg/kg; APP Pharmaceuticals) was injected intravenously into 6- to 10 -wk-old C57BL/6 SJL mice as previously described (14). Five days after treatment, the bone marrow was harvested and cultured overnight with the following growth factors: stem cell factor (SCF; $100 \mathrm{ng} / \mathrm{mL}), \mathrm{IL}-3(6 \mathrm{ng} / \mathrm{mL})$, and IL-6 (10 ng/mL; all from Peprotech), and $5 \%(\mathrm{v} / \mathrm{v})$ conditioned medium from WeHi-3 


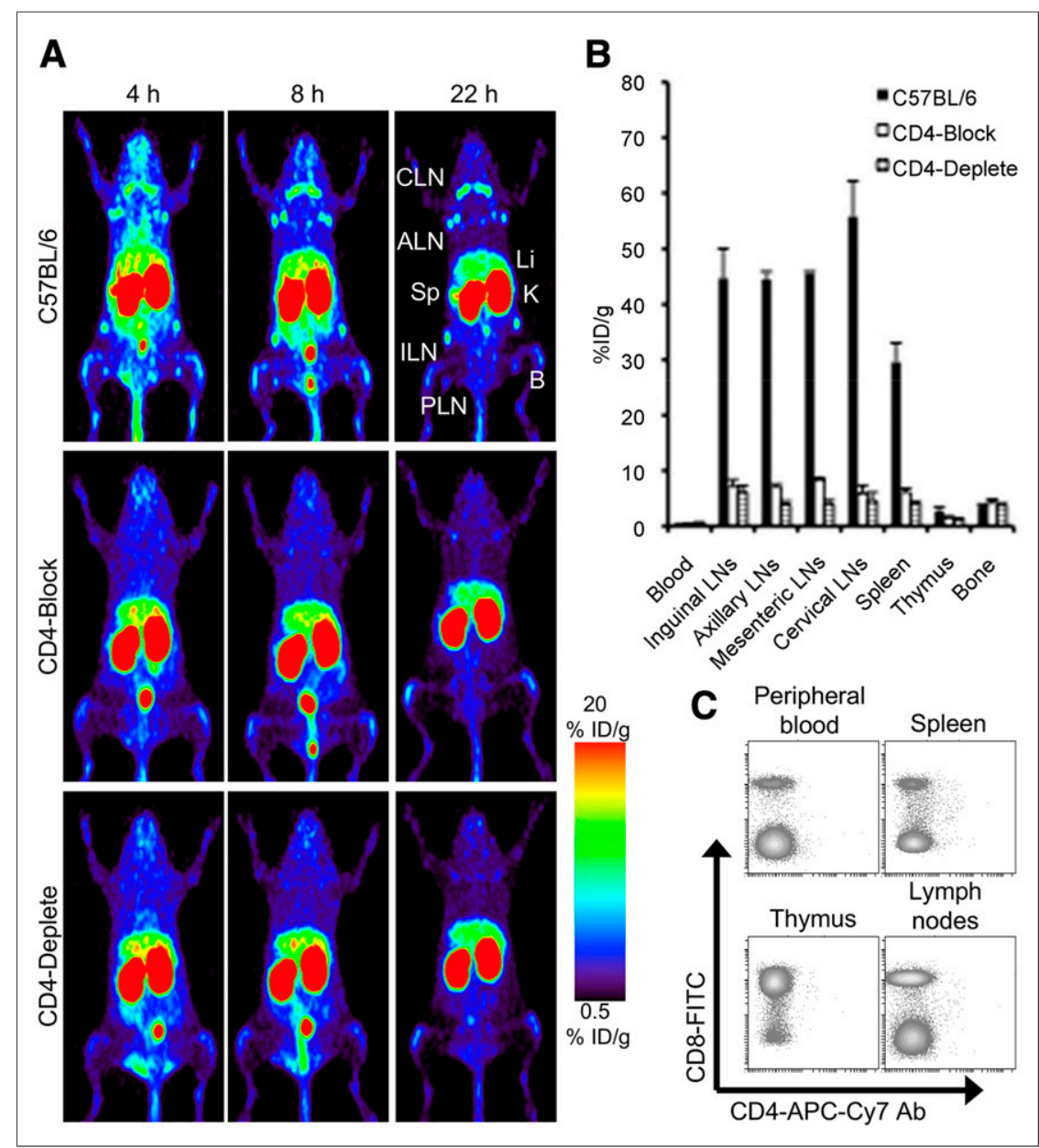

FIGURE 2. Anti-CD4 small-animal PET of ${ }^{89} \mathrm{Zr}$-malDFO-GK1.5 cDb in wild-type, CD4-blocked, and CD4-depleted C57BL/6 mice. (A) ${ }^{89} \mathrm{Zr}$-malDFO-GK1.5 cDb was injected into wild-type (top), CD4-blocked (bolus, GK1.4 cDb [3 mg/kg]; middle), and CD4-depleted (3 consecutive intraperitoneal injections of GK1.5 Ab [25 mg/kg] over $3 \mathrm{~d}$; bottom) C57BL/6 mice and imaged at 4, 8, and $22 \mathrm{~h}$ after injection. Images are represented as $25-\mathrm{mm}$ maximum-intensity projections. (B) Ex vivo biodistribution at $22 \mathrm{~h}$ after injection of $89 \mathrm{Zr}$-malDFO-GK1.5 cDb from wild-type, CD4-blocked, and CD4-depleted C57BL/6 mice. (C) Flow cytometry of single-cell suspensions from blood, thymus, spleen, and LNs of CD4-depleted C57BL/6 mice confirms depletion of CD4-expressing cells. $A b=$ antibody; $A L N=$ axillary $L N ; B=$ bone; $C L N=$ cervical $L N ; F I T C=$ fluorescein isothiocyanate; $\mathrm{ILN}=$ inguinal $\mathrm{LN} ; \mathrm{K}=$ kidney; $\mathrm{Li}=$ liver; $\mathrm{PLN}=$ popliteal $\mathrm{LN} ; \mathrm{Sp}=$ spleen.

cells (American Type Culture Collection). HSCs $\left(5 \times 10^{5}\right)$ were injected intravenously into 8 -wk-old C57BL/6 mice that had been lethally irradiated $(900 \mathrm{rad})$ on the same day.

\section{RESULTS}

\section{Anti-CD4 GK1.5 cDb Characterization}

The anti-CD4 GK1.5 cDb was successfully engineered, produced, and purified, with a final purified yield of $0.36 \mathrm{mg} / \mathrm{L}$. The purity and molecular weight of the $\mathrm{cDb}$ were confirmed by SDSPAGE and SEC (Figs. 1B and 1C). After mild reduction, GK1.5 $\mathrm{cDb}$ was conjugated to Alexa Fluor 488 C5-maleimide (Life Technologies; mal488) with a recovery of $61 \%$ after purification. The conjugation resulted in a dye-to-protein molar ratio of 1.5:1, and the mal488 was bound to the monomeric protein as seen by SDS-PAGE analysis and fluorescent imaging of the gel (Fig. 1B). Importantly, the elution profiles of the GK1.5 cDb and the mal488-GK1.5 cDb on SEC were similar ( $~ 55 \mathrm{kDa})$, demonstrat- ing that the conjugation to the Cys-tag had not disrupted the diabody conformation (Fig. 1C). Mal488-GK1.5 cDb binds to primary cells isolated from the peripheral blood, thymus, spleen, and lymph nodes (LNs) of C57BL/6 (BL/6) mice similarly to the commercial GK1.5-APC-Cy7 antibody (Fig. 1D).

\section{Anti-CD4 GK1.5 cDb Targets CD4 ${ }^{+} \mathrm{T}$ Cells In Vivo}

Conjugation of the GK1.5 cDb to malDFO did not alter the size-exclusion profile of the DFO-conjugated protein (Supplemental Fig. 1). The malDFO-GK1.5 cDb was radiolabeled with ${ }^{89} \mathrm{Zr}$ with a radiolabeling efficiency of $96.9 \% \pm 1.5 \%$ (range, $94 \%$ $98 \%, n=5$ ). After spin column purification, the radiochemical purity was greater than $99.5 \%$ as shown by ITLC. The specific activity was $155 \pm 59 \mathrm{kBq} / \mu \mathrm{g}(4.2 \pm$

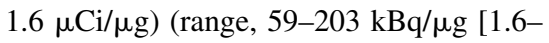
$5.5 \mu \mathrm{Ci} / \mu \mathrm{g}] ; n=5)$.

Protein doses of $11.8 \pm 1.4 \mu \mathrm{g}$ (range, 10.3-14 $\mu \mathrm{g}, n=5$ ) were injected intravenously via the tail into BL/6 mice. Immuno-PET acquisition at 4,8 , and $22 \mathrm{~h}$ after injection showed a decrease in radioactivity in the heart over time, demonstrating blood clearance and high-contrast images at $22 \mathrm{~h}$ after injection, with uptake in various lymphoid organs and the kidney (Fig. 2A, top). Targeting to the LNs and spleen was confirmed by ex vivo biodistribution at $22 \mathrm{~h}$ after injection (Fig. 2B; Supplemental Table 1). Interestingly, targeting to the thymus was not similar to other lymphoid organs.

To evaluate specificity, the ${ }^{89} \mathrm{Zr}-$ malDFO$\mathrm{GK} 1.5 \mathrm{cDb}$ was injected into BL/6 mice that received either a bolus coinjection of nonradiolabeled GK1.5 cDb (3 $\mathrm{mg} / \mathrm{kg})$ or anti-CD4 antibody depletion treatment. Immuno-PET of CD4-blocked and CD4-depleted mice showed more rapid clearance from the blood at $4 \mathrm{~h}$ after injection and lower uptake in lymphatic organs when compared with wild-type BL/6 mice (Fig. 2A). Ex vivo biodistribution of CD4-blocked and CD4depleted BL/6 mice confirmed a significant decrease in the LNs, spleen, and thymus when compared with wild-type BL/6 mice (Fig. 2B; Supplemental Table 1). Taken together, these results confirm specific targeting of ${ }^{89} \mathrm{Zr}$-malDFO-GK1.5 $\mathrm{cDb}$ to lymphoid organs.

\section{Anti-CD8 $2.43 \mathrm{cDb}$ Characterization}

The previously engineered anti-CD8 2.43 Mb (22) was successfully reengineered as $\mathrm{a} \mathrm{cDb}$ and purified at high purity (Supplemental Fig. 2), with a yield of $2.44 \mathrm{mg} / \mathrm{L}$. Superdex $75 \mathrm{SEC}$ confirmed the correct molecular weight of approximately $55 \mathrm{kDa}$ (Supplemental Fig. S2).

The $2.43 \mathrm{cDb}$ was conjugated to mal488 with a recovery of $64 \%$ after purification, with a dye-to-protein molar ratio of $0.9: 1$. The 


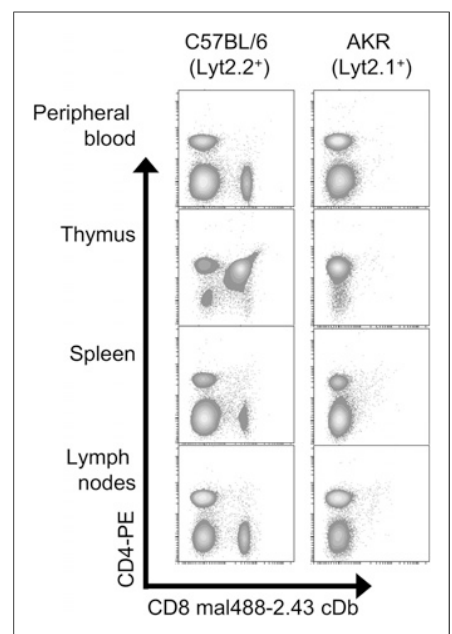

FIGURE 3. Engineered anti-CD8 $2.43 \mathrm{cDb}$ retains antigen specificity. Flow cytometry of single-cell suspenand LNs of Lyt2.2 ${ }^{+}$C57BL/6 (left) and Lyt2. $1^{+}$AKR mice (right) demonstrates that mal $488-2.43 \mathrm{cDb}$ retains its antigenbinding specificity. $\mathrm{PE}=$ phycoerythrin. gated to malDFO (Supplemental Fig. 2) and radiolabeled with ${ }^{89} \mathrm{Zr}$ with a radiolabeling efficiency of $85.5 \% \pm 12.5 \%$ (range, $66 \%-97 \%, n=6$ ), and the radiochemical purity was greater than $99.4 \%$ as shown by ITLC. sions from blood, thymus, spleen,

The specific activity was $126 \pm 33 \mathrm{kBq} / \mu \mathrm{g}(3.4 \pm 0.9 \mu \mathrm{Ci} / \mu \mathrm{g})$ (range, $92-170 \mathrm{kBq} / \mu \mathrm{g}[2.5-4.6 \mu \mathrm{Ci} / \mu \mathrm{g}] ; n=5$ ).

Protein doses of $10.9 \pm 0.6 \mu \mathrm{g}$ (range, $10-11.6 \mu \mathrm{g}, n=6$ ) of ${ }^{89} \mathrm{Zr}$-malDFO-2.43 $\mathrm{cDb}$ were injected intravenously into either wild-type BL/6 mice (Fig. 4A, top) or BL/6 mice that received a bolus coinjection of $3 \mathrm{mg} / \mathrm{kg}$ nonradiolabeled $2.43 \mathrm{cDb}$ (Fig. 4B, bottom). Immuno-PET images of ${ }^{89} \mathrm{Zr}$-malDFO-2.43 $\mathrm{cDb}$ in wildtype BL/6 mice show high background at $4 \mathrm{~h}$ after injection that cleared by $22 \mathrm{~h}$ for high-contrast images. Ex vivo biodistribution of ${ }^{89} \mathrm{Zr}$-malDFO-2.43 $\mathrm{cDb}$ acquired at $22 \mathrm{~h}$ after injection in wildtype and CD8-blocked BL/6 mice showed significantly less uptake in the spleen and LNs of CD-8 blocked mice, demonstrating CD8 specificity in vivo (Fig. 4B; Supplemental Table 2). Targeting to the thymus of ${ }^{89} \mathrm{Zr}$-malDFO-2.43 cDb was low, and CD8blocking did not decrease uptake.

\section{T Cell Repopulation After HSC Transplantation}

BL/6 SJL $\left(C D 45.1^{+}\right)$HSCs were intravenously injected into lethally irradiated BL/6 (CD45.2 $2^{+}$) mice to enable the distinction between donor and host lymphocytes at 2, 4, and 8 wk after HSC transplantation using flow cytometry (Fig. 5). At 2 wk after HSC transplantation, the total donor cells were high in the peripheral blood and low in both the LNs and the spleen. By $8 \mathrm{wk}$, however, the donor cells are about $85 \%$ of the total $\mathrm{CD} 45^{+}$cells in the $\mathrm{LNs}$, spleen, and peripheral blood, demonstrating efficient HSC engraftment and $\mathrm{T}$ cell repopulation.

When the $\mathrm{CD}^{+} \mathrm{T}$ cell engraftment (Fig. 5, middle) was analyzed, the total CD4 numbers at 2 wk after HSC transplantation were low in the peripheral blood and spleen (about $5 \%$ and $3 \%$, respectively) but high in the LNs ( $\sim 40 \%)$, with most of the $\mathrm{CD}^{+} \mathrm{T}$ cells being of host origin. At $4 \mathrm{wk}$, the total $\mathrm{CD}^{+}{ }^{+} \mathrm{T}$ cells in the peripheral blood and spleen increased to about $12 \%$, with most of the $\mathrm{CD}^{+}{ }^{+} \mathrm{T}$ cells from donor origin. Interestingly, the total number of $\mathrm{CD}^{+}{ }^{+} \mathrm{T}$ cells in the LNs at 4 wk decreased $(\sim 28 \%)$, but the percentage of donor CD4 ${ }^{+} \mathrm{T}$ cells increased, compared with the engraftment at 2 wk after HSC transplantation. By 8 wk, the total $\mathrm{CD}^{+}{ }^{+} \mathrm{T}$ cells in the LNs, peripheral blood, and spleen were approximately $35 \%, 22 \%$, and $18 \%$, respectively, with most of $\mathrm{CD}^{+}{ }^{+} \mathrm{T}$ cells being of donor origin. Total CD8 cell numbers and repopulation of donor $\mathrm{CD}^{+} \mathrm{T}$ cells at 2, 4, and 8 wk after HSC transplantation (Fig. 5, bottom) were similar to those of $\mathrm{CD} 4$, but the total numbers of $\mathrm{CD}^{+} \mathrm{T}$ cells were about half of the total $\mathrm{CD}^{+}{ }^{+} \mathrm{T}$ cells. Thus, flow cytometry demonstrated effective repopulation of $\mathrm{CD}^{+}$and $\mathrm{CD}^{+} \mathrm{T}$ cells over time.

FIGURE 4. Anti-CD8 small-animal PET/CT of ${ }^{89} \mathrm{Zr}$-malDFO-2.43 cDb in wild-type and CD8blocked C57BL/6 mice. (A) ${ }^{89} \mathrm{Zr}$-malDFO-2.43 cDb was injected into wild-type (top) and CD8blocked (bolus, $2.43 \mathrm{cDb}$ [3 mg/kg]; bottom) C57BL/6 mice and imaged at 4, 8, and $22 \mathrm{~h}$ after injection. Images are represented as coronal $25-\mathrm{mm}$ maximum-intensity projections. (B) Transverse CT and PET/CT 0.5-mm maximum-intensity projections of the inguinal LNs (top) and spleen (bottom) in wild-type C57BL/6 mice at $22 \mathrm{~h}$ after injection show PET coregistration with anatomic CT scans. Bars on coronal scan in top right part of $A$ indicate location of transverse images. (C) Ex vivo biodistribution at $22 \mathrm{~h}$ after injection of ${ }^{89} \mathrm{Zr}$-malDFO-2.43 $\mathrm{cDb}$ from wild-type and CD8blocked C57BL/6 mice. ALN = axillary LN; $\mathrm{B}=$ bone; $\mathrm{CLN}=$ cervical $\mathrm{LN} ; \mathrm{ILN}=$ inguinal $\mathrm{LN} ; \mathrm{K}=$ kidney; $\mathrm{Li}=$ liver; $\mathrm{PLN}=$ popliteal $\mathrm{LN} ; \mathrm{Sp}=$ spleen.

\section{Anti-CD4 and -CD8 Immuno-PET Detection of $\mathrm{T}$ Cell Repopulation}

${ }^{89} \mathrm{Zr}-\mathrm{malDFO}-\mathrm{GK} 1.5 \mathrm{cDb}$ and ${ }^{89} \mathrm{Zr}-$ malDFO-2.43 $\mathrm{cDb}$ were used to image $\mathrm{CD}^{+}{ }^{+}$and $\mathrm{CD} 8{ }^{+} \mathrm{T}$ cell reconstitution, respectively, in vivo at 2,4 , and $8 \mathrm{wk}$ after HSC transplantation (Fig. 6; Supplemental 


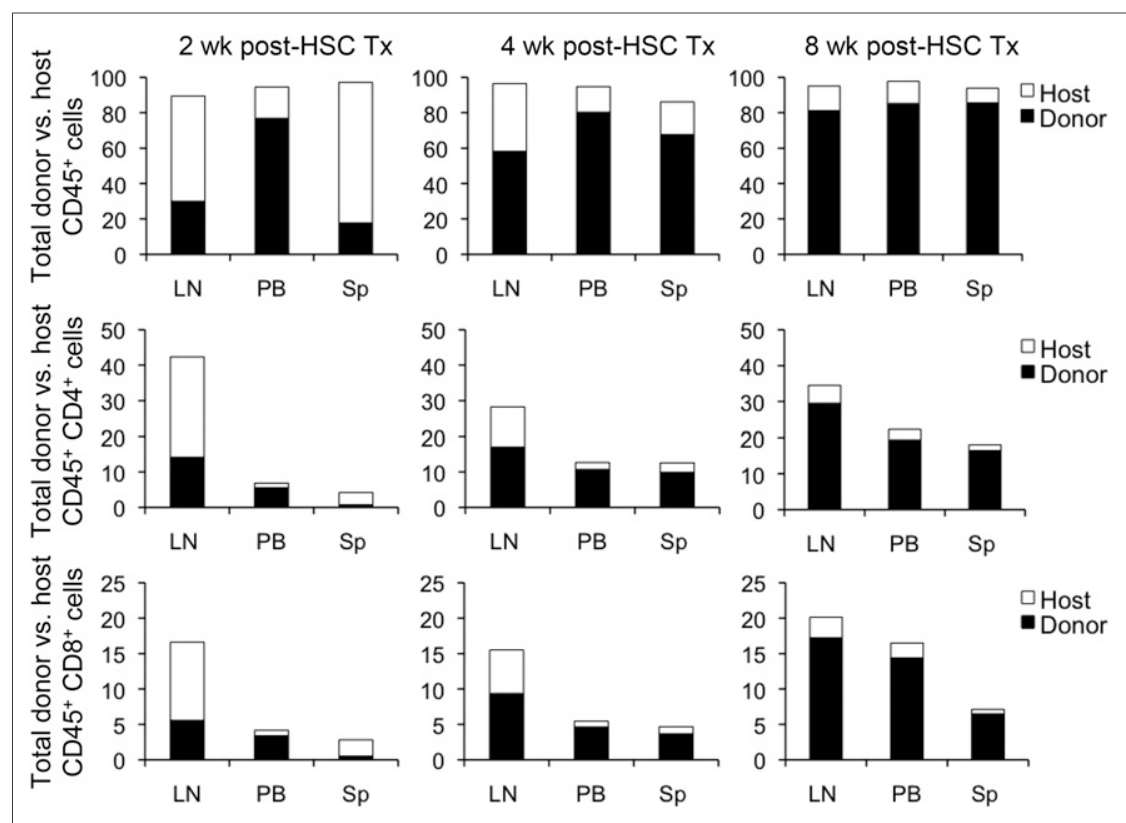

FIGURE 5. Flow cytometry analysis of $\mathrm{CD}^{+}$and $\mathrm{CD} 8^{+} \mathrm{T}$ cell reconstitution. Total donor vs. host cells (top), donor vs. host CD4 ${ }^{+} \mathrm{T}$ cells (middle), and donor vs. host CD8 ${ }^{+} \mathrm{T}$ cells (bottom) at 2 wk (left), 4 wk (middle), and 8 wk (right) after HSC transplantation ( $n=3$ or 4 ). Single-cell suspensions from lymph nodes (LNs), peripheral blood (PB), and spleen (Sp) of mice are stained with anti-CD45.1 (donor), anti-CD45.2 (host), anti-CD4, and anti-CD8 for flow cytometry analysis to quantify CD4 ${ }^{+}$ and $\mathrm{CD}^{+} \mathrm{T}$ cell percentages. $\mathrm{PB}=$ peripheral blood; $\mathrm{Sp}=$ spleen; $\mathrm{Tx}=$ therapy.

Table 3). The detection of the LNs from anti-CD4 and anti-CD8 immuno-PET images in HSC-transplanted mice increased from 2 to 8 wk after HSC transplantation. The biodistribution data of the anti$\mathrm{CD} 4 \mathrm{cDb}$, however, indicate that the percentage injected dose per gram $(\% \mathrm{ID} / \mathrm{g})$ in the LNs for the anti-CD4 repopulation was high at 2 and $4 \mathrm{wk}$ after HSC transplantation (axillary LNs, $75 \pm 11$ and $79 \pm 13 \% \mathrm{ID} / \mathrm{g}$, respectively) and decreased at $8 \mathrm{wk}(39 \pm 8.5$ $\% \mathrm{ID} / \mathrm{g})$. In the spleen, the $\% \mathrm{ID} / \mathrm{g}$ of ${ }^{89} \mathrm{Zr}$-malDFO-GK1.5 $\mathrm{cDb}$ was moderate at $2 \mathrm{wk}$ after HSC transplantation $(16 \pm 2.0 \% \mathrm{ID} / \mathrm{g})$ and then increased at 4 and $8 \mathrm{wk}$ after HSC transplantation $(36 \pm 3.4$ and $33 \pm 3.1 \% \mathrm{ID} / \mathrm{g}$, respectively). The $\% \mathrm{ID} / \mathrm{g}$ for CD8 repopulation in both the spleen and the LNs remained relatively constant from 2 to 8 wk after HSC transplantation (axillary LNs ranged from 18 to $20 \% \mathrm{ID} / \mathrm{g}$ on average and spleen ranged from 17 to $28 \% \mathrm{ID} / \mathrm{g}$ on average).

Representative CT scans at 2, 4, and 8 wk after HSC transplantation demonstrated a visible increase in size of the inguinal $\mathrm{LN}$ over time due to repopulation of the immune system (Supplemental Fig. 3). Inguinal LNs weighed $0.71 \pm 0.12,0.86 \pm 0.20$, and $2.0 \pm$ $0.24 \mathrm{mg}$ at 2,4 , and $8 \mathrm{wk}$ after HSC transplantation, respectively (Supplemental Fig. 3). These weights were used for estimating the total number of cells, the total $\mathrm{CD}^{+}{ }^{+} \mathrm{T}$ cells, and total $\mathrm{CD} 8^{+}$ T cells at 2, 4, and $8 \mathrm{wk}$ after HSC transplantation (Supplemental Fig. 3). Not only do the percentages of donor T cells change as seen by flow cytometry, but also the total number of lymphocytes increased during repopulation, which is visualized by both anti-CD4 and -CD8 immuno-PET.

\section{DISCUSSION}

By engineering the GK1.5 and 2.43 parental antibodies into cDbs, we have developed immuno-PET fragments for the detection of helper $\mathrm{CD}^{+}$and cytotoxic $\mathrm{CD}^{+} \mathrm{T}$ cells in vivo. Importantly, we have demonstrated that both the GK1.5 and the $2.43 \mathrm{cDb}$ retain a true cross-paired diabody conformation after conjugation via the engineered $\mathrm{C}$-terminal cysteine. It is important to verify maintenance of the proper conformation of cDbs because different linker lengths have the potential to induce higher-molecularweight multimers $(23,24)$ or convert into monovalent scFvs after reduction and site-specific conjugation (25). Flow cytometry was used to demonstrate that the GK1.5 and 2.43 cDbs retain the ability to bind primary $\mathrm{CD}^{+}$and $\mathrm{CD}^{+} \mathrm{T}$ cells, respectively. Furthermore, we used small-animal PET in wild-type immunocompetent BL/6 mice in combination with antigen depletion or antigen blocking to demonstrate either CD4 or CD8 specificity in vivo and demonstrated the ability to monitor $\mathrm{T}$ cell repopulation after HSC transplantation.

Mbs $(\sim 80 \mathrm{kDa})$ and $\mathrm{cDbs}(\sim 50 \mathrm{kDa})$ have different routes of clearance due to the renal filtration cutoff of approximately $60 \mathrm{kDa}$. The use of the residualizing radiometals, such as ${ }^{64} \mathrm{Cu}$ and ${ }^{89} \mathrm{Zr}$, conjugated to Mbs or cDbs causes retention of radioactivity in the liver or kidney, respectively. Therefore, the high kidney uptake of both the ${ }^{89} \mathrm{Zr}$ radiolabeled GK1.5 and the $2.43 \mathrm{cDbs}$ is expected. The previously described ${ }^{64} \mathrm{Cu}$-DOTA-2.43 $\mathrm{Mb}$ (22) suffered from aggregation problems leading to rapid clearance and high liver uptake, but the rapid clearance allowed for high target-to-background images at only $4 \mathrm{~h}$ after injection. In the current work, the nonaggregating ${ }^{89} \mathrm{Zr}$-malDFO-2.43 cDb demonstrated slower blood clearance than the respective $2.43 \mathrm{Mb}$, and the improved time for imaging was $22 \mathrm{~h}$ after injection when the blood activity was $0.61 \pm 0.06 \% \mathrm{ID} / \mathrm{g}$ and inguinal LN-to-blood and spleen-to-blood ratios were 78:1 and $67: 1$, respectively. Previously, the $2.43 \mathrm{Mb}$ derived from a CD8-depleting rat IgG2a antibody was shown to be nondepleting in vivo because of the lack of the complete Fc domain (22). The GK1.5 and 2.43 cDbs described in this work also lack the Fc domain and are expected to be nondepleting, which is critical in the development of immune cell-targeting imaging agents.

An inherent problem of PET imaging of objects near or below the resolution of the PET scanner is the partial-volume effect whereby the activity in a small organ is underestimated because of image reconstruction, attenuation, and positron path length before annihilation (26). Given the small-animal scanner resolution of $1.4 \mathrm{~mm}$ in full width at half maximum, LNs of about $1 \mathrm{~mm}$ in wildtype mice, and the average positron path length of $1.1 \mathrm{~mm}$ for ${ }^{89} \mathrm{Zr}$, a discrepancy exists between the $\% \mathrm{ID} / \mathrm{g}$ in $\mathrm{LNs}$ obtained from PET imaging compared with the ex vivo biodistribution values. This discrepancy can be overcome by the use of partialvolume correction to obtain accurate uptake values in small organs from PET images, and our laboratory has derived recovery coefficients for both ${ }^{89} \mathrm{Zr}$ and ${ }^{124} \mathrm{I}$ using the Inveon microPET scanner (27). Partial-volume correction of LNs, especially when reduced in size at $2 \mathrm{wk}$ after HSC transplantation, will suffer from error due to the small volume regions of interest in which the recovery 


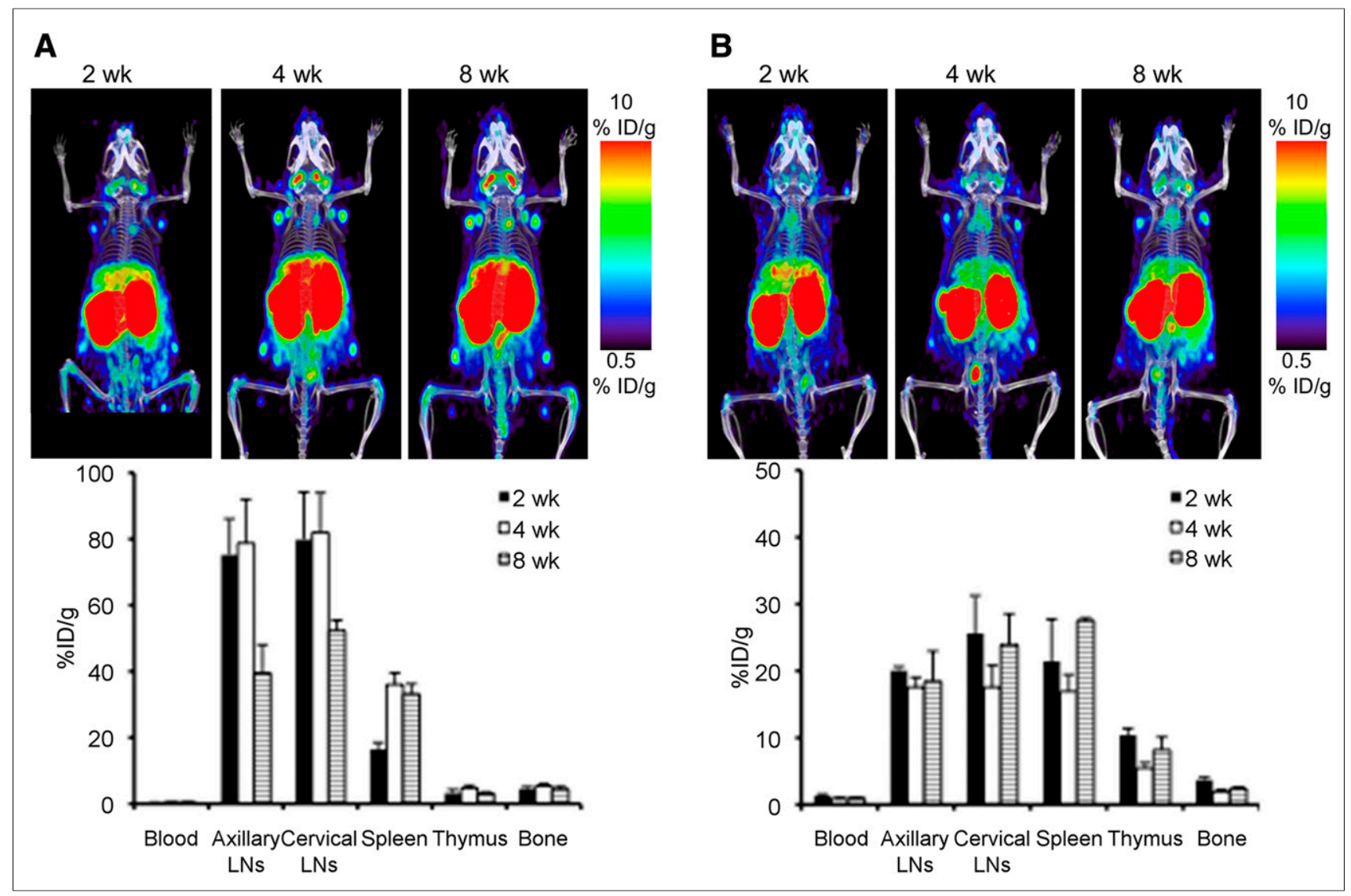

FIGURE 6. Anti-CD4 and -CD8 ${ }^{89} \mathrm{Zr}$ small-animal PET/CT of T cell reconstitution after HSC transplantation. ${ }^{89} \mathrm{Zr}$-malDFO-GK1.5 cDb (A) and ${ }^{89} \mathrm{Zr}-$ malDFO-2.43 cDb (B) were injected into C57BL/6 mice at 2, 4, and $8 \mathrm{wk}$ after HSC transplantation. Immuno-PET images were acquired at $22 \mathrm{~h}$ after injection. Bottom panels are ex vivo biodistributions at $22 \mathrm{~h}$ after injection.

coefficient changes greatly for small changes in volume and the detectability of the LNs.

Although detection of activity in LNs is underestimated using PET, we successfully detected $\mathrm{CD} 4^{+}$and $\mathrm{CD}^{+} \mathrm{T}$ cell reconstitution at 2, 4, and $8 \mathrm{wk}$ after HSC transplantation using the ${ }^{89} \mathrm{Zr}$ malDFO-GK1.5 and ${ }^{89} \mathrm{Zr}$-malDFO-2.43 cDbs. Detection at $2 \mathrm{wk}$ after HSC transplantation proved more difficult because the $\mathrm{LN}$ size is small after irradiation. We were able to detect $\mathrm{CD}^{+}{ }^{+} \mathrm{T}$ cells by immuno-PET at $75 \pm 11 \% \mathrm{ID} / \mathrm{g}$ but not $\mathrm{CD}^{+} \mathrm{T}$ cells at $20 \pm 0.60$ $\% \mathrm{ID} / \mathrm{g}$ in $\mathrm{LNs}$ of the same size $(0.74 \pm 0.12 \mathrm{mg})$, demonstrating that if enough activity accumulates in a small organ, it is detectable by PET. The partial-volume effect is also evident over the $8 \mathrm{wk}$ after HSC transplantation using the anti-CD8 ${ }^{89} \mathrm{Zr}-\mathrm{malDFO}-2.43 \mathrm{cDb}$. The ex vivo biodistributions of ${ }^{89} \mathrm{Zr}$-malDFO-2.43 $\mathrm{cDb}$ at 2,4 , and $8 \mathrm{wk}$ after HSC transplantation in the LNs were consistently around 20-25\% $\%$ ID/g, but the corresponding immuno-PET images show an increase of signal in the LNs from 2 to 8 wk after HSC transplantation. This increased detection is due to the increased size of the LNs over time resulting from immune cell repopulation. PET images of the HSC transplantation model were scaled to the same $\% \mathrm{ID} / \mathrm{g}$ for consistent representation.

Interestingly, the thymus showed low uptake in wild-type mice using anti-CD4 and -CD8 cDbs when compared with other T cellrich lymphoid organs such as the LNs and the spleen, limiting their use as thymic immuno-PET imaging agents. The parental anti-CD4 GK1.5 and anti-CD8 2.43 intact antibodies deplete
CD4- or CD8-expressing cells in the thymus during antibodybased depletion therapy, so it is possible that the full $\mathrm{Fc}$ is required for efficient targeting to the thymus.

Immuno-PET and reporter genes provide different information in the context of $\mathrm{T}$ cell receptor use in hematopoietic stem or progenitor cell therapy. Reporter genes allow for reporter probe uptake in the stem or progenitor cells primarily transduced and all successive cell types, such as T cells, B cells, monocytes, and macrophages (14). Reporter genes provide an indication of total engraftment of donor cells but lack specificity for cell lineages. On the other hand, antibody-based immuno-PET targeting lymphocytes provides an indication of CD4 or CD8 lymphocyte reconstitution but cannot distinguish between host and donor lymphocytes. Imaging $\mathrm{T}$ cell expansion and localization, specifically tumor targeting, using lymphocyte-specific immuno-PET could aid the monitoring of immunotherapeutic efficacy. In combination, reporter gene and CD4- and CD8-based immuno-PET can provide information pertaining to the success of HSC transplantation that was previously impossible.

\section{CONCLUSION}

Anti-CD4 and -CD8 immuno-PET is a robust method for the detection of lymphocytes in vivo and was shown to detect $\mathrm{T}$ cell repopulation in a model of syngeneic HSC transplantation. We believe immuno-PET using radiolabeled antibody fragments 
specific for cell surface lineage markers will greatly aid the ability to monitor the dynamic nature of $\mathrm{T}$ cell subsets in models of disease and expand our knowledge of both $\mathrm{T}$ cells in vivo and immunotherapies.

\section{DISCLOSURE}

The costs of publication of this article were defrayed in part by the payment of page charges. Therefore, and solely to indicate this fact, this article is hereby marked "advertisement" in accordance with 18 USC section 1734 . This work was supported by the UCLA Scholars in Oncologic Molecular Imaging training program (National Institutes of Health [NIH] R25T CA098010), NIH grants R21 AI114255 and R21 CA190044, and by the California Institute for Regenerative Medicine (CIRM; RT1-01126-1). Melissa N. McCracken is supported by the CIRM training grant TG2-01169 and the UCLA In Vivo Cellular and Molecular Imaging Center Career Development Award P50 CA086306. Owen N. Witte is an investigator of the Howard Hughes Medical Institute and is partially supported by the Eli and Edythe Broad Center of Regenerative Medicine and Stem Cell Research. Small-animal imaging studies were supported by the UCLA Jonsson Comprehensive Cancer Center (NIH CA016042). Anna M. Wu has ownership interest in and is a consultant/advisory board member for Imagi$\mathrm{nAb}$, Inc. Richard Tavaré is a consultant to ImaginAb, Inc. Tove Olafsen was a consultant to ImaginAb, Inc., at the time the research was performed and is currently an employee of ImaginAb, Inc. Part of the technology described in this manuscript is licensed by the Regents of the University of California to ImaginAb, Inc., and the Regents have taken equity in ImaginAb, Inc., as part of the licensing transaction. No other potential conflict of interest relevant to this article was reported.

\section{ACKNOWLEDGMENTS}

We thank Dr. Waldemar Ladno, Darin Williams, and Dr. David Stout at the UCLA Crump Institute for Molecular Imaging for help with small-animal PET scans. We also thank Ralph and Marjorie Crump for a donation made to UCLA Crump Institute for Molecular Imaging.

\section{REFERENCES}

1. Wu AM, Senter PD. Arming antibodies: prospects and challenges for immunoconjugates. Nat Biotechnol. 2005;23:1137-1146.

2. Wu AM. Antibodies and antimatter: the resurgence of immuno-PET. J Nucl Med. 2009;50:2-5.

3. Knowles SM, Wu AM. Advances in immuno-positron emission tomography: antibodies for molecular imaging in oncology. J Clin Oncol. 2012;30:38843892.

4. Wu AM. Engineered antibodies for molecular imaging of cancer. Methods. 2014;65:139-147.

5. Matsui K, Wang Z, McCarthy TJ, Allen PM, Reichert DE. Quantitation and visualization of tumor-specific $\mathrm{T}$ cells in the secondary lymphoid organs during and after tumor elimination by PET. Nucl Med Biol. 2004;31:1021-1031.

6. Pittet MJ, Grimm J, Berger CR, et al. In vivo imaging of $\mathrm{T}$ cell delivery to tumors after adoptive transfer therapy. Proc Natl Acad Sci USA. 2007;104: $12457-12461$.
7. Griessinger CM, Kehlbach R, Bukala D, et al. In vivo tracking of Th1 cells by PET reveals quantitative and temporal distribution and specific homing in lymphatic tissue. J Nucl Med. 2014;55:301-307.

8. Koya RC, Mok S, Comin-Anduix B, et al. Kinetic phases of distribution and tumor targeting by $\mathrm{T}$ cell receptor engineered lymphocytes inducing robust antitumor responses. Proc Natl Acad Sci USA. 2010;107:14286-14291.

9. Aarntzen EH, Srinivas M, De Wilt JH, et al. Early identification of antigenspecific immune responses in vivo by $\left[{ }^{18} \mathrm{~F}\right]$-labeled 3 '-fluoro- 3 '-deoxythymidine ([ ${ }^{18}$ F]FLT) PET imaging. Proc Natl Acad Sci USA. 2011;108: 18396-18399.

10. Nair-Gill E, Wiltzius SM, Wei XX, et al. PET probes for distinct metabolic pathways have different cell specificities during immune responses in mice. $J$ Clin Invest. 2010;120:2005-2015.

11. Radu CG, Shu CJ, Nair-Gill E, et al. Molecular imaging of lymphoid organs and immune activation by positron emission tomography with a new $\left[{ }^{18} \mathrm{~F}\right]$-labeled $2^{\prime}$ deoxycytidine analog. Nat Med. 2008;14:783-788.

12. Ribas A, Benz MR, Allen-Auerbach MS, et al. Imaging of CTLA4 blockadeinduced cell replication with ${ }^{18} \mathrm{~F}$-FLT PET in patients with advanced melanoma treated with tremelimumab. J Nucl Med. 2010;51:340-346.

13. Namavari M, Chang YF, Kusler B, Yaghoubi S, Mitchell BS, Gambhir SS. Synthesis of $2^{\prime}$-deoxy-2' $-\left[{ }^{18} \mathrm{~F}\right]$ fluoro-9-beta-D-arabinofuranosylguanine: a novel agent for imaging T-cell activation with PET. Mol Imaging Biol. 2011;13:812818.

14. McCracken MN, Gschweng EH, Nair-Gill E, et al. Long-term in vivo monitoring of mouse and human hematopoietic stem cell engraftment with a human positron emission tomography reporter gene. Proc Natl Acad Sci USA. 2013;110:18571862.

15. Yaghoubi SS, Campbell DO, Radu CG, Czernin J. Positron emission tomography reporter genes and reporter probes: gene and cell therapy applications. Theranostics. 2012;2:374-391.

16. Wirth T, Parker N, Yla-Herttuala S. History of gene therapy. Gene. 2013;525: $162-169$.

17. De Oliveira SN, Ryan C, Giannoni F, et al. Modification of hematopoietic stem/ progenitor cells with CD19-specific chimeric antigen receptors as a novel approach for cancer immunotherapy. Hum Gene Ther. 2013;24:824-839.

18. Vatakis DN, Arumugam B, Kim SG, Bristol G, Yang O, Zack JA. Introduction of exogenous T-cell receptors into human hematopoietic progenitors results in exclusion of endogenous T-cell receptor expression. Mol Ther. 2013;21:10551063.

19. Vatakis DN, Koya RC, Nixon CC, et al. Antitumor activity from antigen-specific CD8 $\mathrm{T}$ cells generated in vivo from genetically engineered human hematopoietic stem cells. Proc Natl Acad Sci USA. 2011;108:E1408-E1416.

20. Yang L, Baltimore D. Long-term in vivo provision of antigen-specific $\mathrm{T}$ cell immunity by programming hematopoietic stem cells. Proc Natl Acad Sci USA. 2005;102:4518-4523.

21. Gschweng EH, McCracken MN, Kaufman ML, et al. HSV-sr39TK positron emission tomography and suicide gene elimination of human hematopoietic stem cells and their progeny in humanized mice. Cancer Res. 2014;74:5173-5183.

22. Tavaré R, McCracken MN, Zettlitz KA, et al. Engineered antibody fragments for immuno-PET imaging of endogenous CD8 + T cells in vivo. Proc Natl Acad Sci USA. 2014;111:1108-1113.

23. Kortt AA, Lah M, Oddie GW, et al. Single-chain Fv fragments of antineuraminidase antibody NC10 containing five- and ten-residue linkers form dimers and with zero-residue linker a trimer. Protein Eng. 1997;10:423433.

24. Kelly MP, Lee FT, Tahtis K, et al. Tumor targeting by a multivalent single-chain Fv (scFv) anti-Lewis Y antibody construct. Cancer Biother Radiopharm. 2008;23: 411-423.

25. Tavaré R, Wu WH, Zettlitz KA, et al. Enhanced immunoPET of ALCAMpositive colorectal carcinoma using site-specific ${ }^{64} \mathrm{Cu}$-DOTA conjugation. Protein Eng Des Sel. 2014;27:317-324.

26. Soret M, Bacharach SL, Buvat I. Partial-volume effect in PET tumor imaging. J Nucl Med. 2007;48:932-945.

27. Knowles SM, Zettlitz KA, Tavaré R, et al. Quantitative immunoPET of prostate cancer xenografts with ${ }^{89} \mathrm{Zr}$ - and ${ }^{124} \mathrm{I}$-labeled anti-PSCA A11 minibody. J Nucl Med. 2014;55:452-459. 